$5^{\text {th }}$ International Conference on Innovation in Science and Technology

Barcelona - Spain

ISTCONF

7 - 9 December, 2018

\title{
CHROMATOGRAPHIC SEPARATION OF PEPTIDES-PROTEINS FROM Microcystis aeruginosa
}

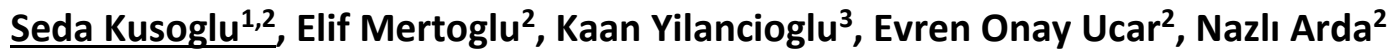 \\ ${ }^{1}$ Üsküdar University, Faculty of Engineering and Natural Sciences, Department of Molecular Biology and Genetics \\ ${ }^{2}$ İstanbul University, Faculty of Science, Department of Molecular Biology and Genetics \\ ${ }^{3}$ Üsküdar University, Faculty of Engineering and Natural Sciences, Department of Chemical and Biological \\ Engineering
}

\begin{abstract}
Microcystis aeruginosa is a species of freshwater cyanobacteria, which are classified among oxygenic photosynthetic bacteria. It is commonly found in drinkable freshwater sources that are not adequately chlorinatied, and able to produce many metabolites harmful to human and animal health, especially during toxin-producing bloom. Here we aimed to separate the major peptides and proteins of Microcystis aeruginosa using HPLC, and to identify their approximate molecular weights by fast silver staining followed by SDS-PAGE, for checking their cytotoxic activities in further studies. For this purpose, Microcystis aeruginosa was incubated at $28^{\circ} \mathrm{C}$ in a shaking incubator at $110 \mathrm{rpm}$ under continuous light source for 21 days in BG-11 medium and the algal cells were lysed using homogenizer. The fractionation of the algal cell extract was performed by using an optimized HPLC method. Separately collected fractions were first concentrated in a lyophilizator, and analyzed by gel electrophoresis utilizing fast silver staining. The determined molecular weights were then matched to the retention times of HPLC separation. The optimized chromatographic and electrophoretic techniques used in this study might be helpful for further studies on both cytotoxic peptides-proteins of Microcystis aeruginosa and their use in precise measurement of enviromental threats arising from Microcystis aeruginosa bloom.
\end{abstract}

Keywords: HPLC, cyanobacteria, Microcystis aeruginosa, SDS-PAGE, algal bloom 